\title{
Políticas de amizade: Portinari e o mundo cultural ibero-americano
}

\section{Friendship policies: Portinari and the Ibero-American World}

\section{Maria de Fátima Fontes Piazza}

O poeta espanhol Rafael Alberti compôs vários versos dedicados à pintura e a alguns pintores, entre os quais se destacam os espanhóis Picasso, Miró, Velázquez, Zurbarán, os pintores do Renascimento italiano, o muralista mexicano David Alfaro Siqueiros e o pintor brasileiro Cândido Portinari.

Quais os vínculos que uniam o poeta da geração de 1927 com o pintor Portinari? O que levou aquele a manter correspondência com o pintor de Brodósqui? Quais as afinidades eletivas entre Portinari e outras personalidades do mundo cultural ibero-americano que viviam exiladas em Buenos Aires ou pertenciam ao círculo das artes - leia-se da literatura e das artes visuais?

Para responder a algumas dessas questões, o ponto de partida foi a série Correspondências do Projeto Portinari, na qual se destacam alguns missivistas que viveram o exílio platino ou participaram ativamente da vida cultural da cosmopolita Buenos Aires na primeira metade do século XX, como Rafael Alberti (1902-1999), o crítico de arte argentino Jorge Romero Brest (1905-1989), o advogado Norberto A. Frontini (18991985), o editor e escritor Newton Freitas (1906-1996), a escritora Lídia Besouchet (1908-1997), o escritor e editor espanhol Guillermo de Torre (1900-1971), e na outra margem do Rio da Prata, no Uruguai, o pintor Carlos Washington Aliseris (1898-1974), o crítico de arte, poeta e escritor Cipriano Santiago Vitureira (1907) e o escritor e poeta Enrique Amorim (1900-1960).

Algumas questôes comuns dizem respeito ao universo político dos países de origem dessas personalidades, como os republicanos Rafael Alberti 
e Guillermo de Torre, que deixaram a Espanha por causa da Guerra Civil Espanhola e da ditadura franquista, dos escritores Lídia Besouchet e Newton Freitas, que, por força da opressão física e simbólica do Estado Novo, saíram do Brasil. Interessante ressaltar que é para o circuito das artes visuais que convergem os assuntos dessa troca de correspondências, as quais se entrecruzam com a trajetória do escritor paulistano Mário de Andrade (1893-1945).

Neste artigo, as correspondências são analisadas como lócus de sociabilidade intelectual, o que permite vislumbrar que "a escrita epistolar é, portanto, uma prática eminentemente relacional e, no caso das cartas pessoais, um espaço de sociabilidade privilegiado para o estreitamento (ou o rompimento) de vínculos entre indivíduos e grupos. Isso ocorre em sentido duplo, tanto porque se confia ao "outro" uma série de informaçóes e sentimentos íntimos, quanto porque cabe a quem lê, e não a quem escreve (o autor/editor), a decisão de preservar o registro. A idéia de pacto epistolar segue essa lógica, pois envolve receber, ler, responder e guardar cartas", como chama atenção Ângela de Castro Gomes ${ }^{2}$.

O corpus documental pesquisado aponta para uma troca de correspondências entre o pintor Cândido Portinari (1903-1962) e alguns interlocutores, como o poeta Rafael Alberti, no período que abrange desde o final da década de 1940 até a morte do pintor. Embora o conjunto aponte somente para 31 correspondências de Alberti para Portinari e uma do pintor para o poeta, os missivistas trocaram telegramas, bilhetes postais e cartas com desenhos de Alberti, o que demonstra uma grande afinidade entre os dois que perpassava o âmbito da esfera pública e penetrava na dimensão do privado. As missivas revelam que suas afinidades eletivas incluíam projetos estéticos e políticos, com muitas referências à intelectualidade do mundo ibero-americano, como aos poetas Pablo Neruda e Nicolás Guillén.

$\mathrm{O}$ poeta chileno, nas suas memórias, menciona que conheceu em Madrid, quando fora nomeado cônsul do Chile na capital espanhola, toda uma geração de poetas, artistas e escritores do mundo ibero-americano, com destaque para os poetas Rafael Alberti, Federico García Lorca, Miguel Hernández, Luís Cernuda, Vicente Alexandre, Juan Ramón Jiménez, Manoel Altolaguirre, Jorge Guillén, além do arquiteto Luís Lacasa, dos pintores Maruja Malo, Antonio Aparício, José Caballero, dos escritores Valle Inclán, Ramón Gómez de la Serna, Antonio Machado, entre muitos outros. 
O poeta chileno evoca Alberti como um "militante do povo" ou um intelectual engajado nas causas políticas do seu país - daí a preocupação social na arte - e o descreve poeticamente como forjado no "esplendor da poesia" de língua espanhola:

Conheci-o militante do povo quando não tinha muitos poetas que exercessem esse destino difícil. Ainda não tinham dobrado os sinos pela Espanha, mas ele já sabia o que podia vir. Ele é um homem do Sul, nasceu junto ao mar sonoro e às adegas de vinho amarelo como topázio. Assim foi feito seu coração; com o fogo das uvas e o rumor da onda. Sempre foi um poeta, ainda que no início não o soubesse. [...] Rafael Alberti significa o esplendor da poesia na língua espanhola. Não só é um poeta inato, mas um mestre da forma. Sua poesia tem, como uma rosa vermelha milagrosamente desabrochada no inverno, um copo de neve de Góngora, uma raiz de Jorge Manrique, uma pétala de Garcilaso, um aroma enlutado de Gustavo Adolfo Bécquer. $\mathrm{O}$ que quer dizer que em sua taça cristalina confundem-se os cantos essenciais da Espanha. Esta rosa vermelha iluminou o caminho dos que na Espanha pretenderam deter o fascismo. $\mathrm{O}$ mundo conhece esta heróica e trágica história. Alberti não só escreveu sonetos épicos, não só os leu nos quartéis e no front como foi quem inventou a guerrilha poética a guerra poética contra a guerra. Inventou canções que criaram asas sob o estampido da artilharia, canções que depois vão voando sobre a terra. Este poeta de puríssima estirpe ensinou a utilidade pública da poesia num momento crítico do mundo. Nisso se assemelha a Maiakovski ${ }^{3}$.

$\mathrm{Na}$ trajetória de vida desses dois poetas, um sul-americano e o outro espanhol, existe em comum a militância política que posteriormente resultará na adesão ao Partido Comunista. A mesma postura política será assumida por Portinari, quando em 1945 filia-se ao Partido Comunista Brasileiro (PCB), candidatando-se a uma vaga de Deputado Federal pelo Estado de São Paulo, sendo derrotado, e nas eleições de 19 de janeiro de 1947 concorre a uma vaga para o Senado da República, para o qual não é eleito por uma pequena margem de votos. Com o cancelamento do registro do PCB pelo Tribunal Superior Eleitoral, sob a alegação de que se tratava de uma organização internacional a serviço de Moscou, e também com o fechamento da Escola do Povo, criada em 1946, na qual Portinari se engajara como professor, o que resultara num inquérito policial que se prolongou por vários anos, Portinari opta por um exílio no Uruguai de 
novembro de 1947 a junho de 1948, para escapar das perseguições que o governo Dutra movia contra os comunistas ${ }^{4}$.

Em maio de 1947, Portinari viajou à Argentina, onde conheceu Alberti e o poeta cubano Nicolás Guillén. A partir daí tem início uma amizade e uma troca de correspondências entre Alberti e Portinari que retrata o mundo cultural ibero-americano, com suas produções editoriais, artísticas e literárias. Isto está expresso numa carta do poeta ao pintor, comunicando o envio de dois exemplares de Ver y estimar, revista dirigida pelo crítico de arte argentino Jorge Romero Brest, onde acrescenta:

Él, como verás, te dedica un gran elogio, sincero y entusiasta, con motivo de tu exposición en la Hebraica. La otra noche, que estuvo en mi casa, me habló mucho de ti y admiró los tres dibujos tuyos que tengo en mis paredes. Yo quisiera - y esto es cosa mía - que buscarás entre tus amigos algunas suscripciones para la revista. Resulta muy barata. Está hecha toda por gente joven, alumnos de Romero. [...] Mi libro "A la Pintura" marcha bien, por sus propios pasos, pues aquí la crítica no existe y hay que ser el Espíritu Santo para adivinar la aparición de una nueva obra ${ }^{5}$.

Algumas questôes relevantes sobre a missiva merecem uma análise, como a intensa atuação de Jorge Romero Brest como crítico de arte nos periódicos Sur, Nosotros, Saber Vivir, La Vanguardia, Correo Literario, Plastica e Argentina Libre. Além de exercer uma profícua atividade como professor, conferencista e editor, foi co-diretor da Editorial Argos (19461949) com o historiador José Luis Romero (1909-1977) e o advogado e empresário Luís Miguel Baudizzone (1909-1979). Também foi fundador da revista Ver y Estimar, que dirigiu de 1948 a 1955.

Quanto ao artigo que Brest fez sobre a exposição de Portinari na Ver y Estimar, que está no número 4, de julho de 1948, sob o título Alabanza de Portinari, este vem corroborar com o que Alberti dissera na missiva, da profunda impressão que causou a obra do pintor para o crítico argentino, no qual exalta poeticamente em quatro parágrafos a obra portinariana, como se depreende das seguintes palavras:

Lo alabo porque pinta y dibuja lo que en su mundo vive y muere - aunque lo amplie hacia al mundo de los otros - y lo que duele con ese dolor que no se extingue en la herida siempre abierta de la angustia, su cuaresma y su salvación. Y porque no se agota en la viril protesta y hacia el futuro dispara en lírico canto de esperanza ${ }^{6}$. 
A carta de Alberti revelava, do mesmo modo, a inserção e a integração de Portinari no circuito platino das artes visuais, como comprova a menção à mostra Óleos, Monotipos y Dibujos de Cándido Portinari, que se realizou na Sociedad Hebraica Argentina, em Buenos Aires, de 17 a 30 de junho de 1948. O poeta espanhol faz referência aos dois desenhos do pintor que possuía em sua residência na capital portenha, como "Cabeça de menino" e "Homem Chorando", tão apreciados por Romero Brest, e aproveita para dar notícia do seu livro $A$ la Pintura, cuja primeira edição foi publicada no mesmo ano pela Editorial Losada, de Buenos Aires.

Convém salientar que os projetos políticos e estéticos andavam pari passu no cenário platino, conforme se depreende da troca de correspondências entre vários interlocutores devido à permanência de exilados de diversas procedências naquela região. Na primeira metade do século XX, a cidade de Buenos Aires era o "meridiano de Greenwich literário" da região. Tal posição foi alçada na década de 1920, acompanhada de grandes mudanças no cenário urbano, segundo Beatriz Sarlo:

[...] no se trata sólo de las vanguardias estéticas, de la modernización económica, sino de la modernidad como estilo cultural, que penetra el tejido de una sociedad que no se le resiste, ni en los proyectos de sus élites políticas ni en su densidad de vida. El impacto de los procesos socioeconómicos, iniciados en la última mitad del siglo XIX, alteró no sólo el perfil y la ecología urbana sino el conjunto de experiencias de sus habitantes. Asi, Buenos Aires interesa como espacio físico y como mito cultural ${ }^{7}$.

As correspondências de Mário de Andrade para Cândido Portinari ${ }^{8}$ e de Mário de Andrade para Newton Freitas9 permitem reconstituir a trajetória de algumas personalidades do mundo cultural ibero-americano, especialmente na mítica capital portenha, como a do escritor espanhol Guillermo de Torre.

A vida literária de Guillermo de Torre está ligada ao ultraísmo, em 1919, após a publicação na imprensa madrilenha do manifesto do grupo Ultra - un Manifiesto de la juventud literaria, o qual é o primeiro movimento literário e artístico que reage contra a estagnação das artes na Espanha e procura estimular a experimentação de novas linguagens. $\mathrm{O}$ ultraísmo espanhol não se articulou através de obras poéticas individuais, mas a partir de inúmeros periódicos do movimento ${ }^{10}$. 
Também existiram periódicos de vida efêmera, como Tableros (19211922), com quatro números, Perseo (maio de 1919), Reflector (dezembro de 1920), Vértices (outono de 1923) e Tobogán (agosto de 1924); Horizonte, arte, literatura, crítica (novembro/dezembro de 1922), que se apresenta como uma revista de posição teórica mais crítica, no qual aparece uma resenha do volume de Guillermo de Torre, Hélices (1918-1922), que julga o ultraísmo perigoso e ultrapassado e é a ponta de lança da geração de 1927, com Gerardo Diego, Rafael Alberti, Federico García Lorca e Nicolás Guillén.

Os introdutores dessas experiências das vanguardas européias em Buenos Aires foram os irmãos Norah e Jorge Luis Borges, que foram receptivos ao ultraísmo espanhol, ao expressionismo alemão e ao cubismo francês. $\mathrm{O}$ transoceanismo das linguagens modernas pode ser vislumbrado no cosmopolitismo da revista Martín Fierro e nas advertências de Guillermo de Torre quando escreve um artigo no periódico espanhol La Gaceta Literaria, sob o título Madrid Meridiano Intelectual de HispanoAmérica, no qual chama a atenção dos escritores argentinos de estarem absorvendo a estética francesa e sugere que se deixem influenciar pela arte de Madrid. A visão "colonialista" de Torre gera uma reação nacionalista dos grupos de Martín Fierro e Boedo, e é a partir desta reação que Nicolás Olivari comenta que Borges abandona o ultraísmo espanhol em prol da argentinidad e desfralda a bandeira do criollismo de Martín Fierro ${ }^{11}$.

Aqui se esboça uma questão central do campo cultural ibero-americano, a coexistência da tradição e da modernidade. Apesar do propalado cosmopolitismo de Martín Fierro, a questão da identidade nacional da Argentina estava cada vez mais presente na produção literária e artística daquele país, pois esta se vincula ao desejo de autonomia do campo cultural em processo de formação. A historiadora da arte Maria Lúcia Bastos Kern chama a atenção para isso:

[...] tanto para construir a modernidade estética, como a nova identidade torna-se imprescindível à criação de sistemas de representação simbólica inovadores que tem como fundamentos os signos de argentinidad e da vida cotidiana moderna. Enquanto os signos nacionais são usados para demarcar as especificidades e as diferenças culturais, os signos da modernidade nem sempre são reveladores destas peculiaridades ${ }^{12}$.

Mário de Andrade, na série publicada no "Diário Nacional" sob o título Literatura Modernista Argentina, chama a atenção para "uma reação 
violenta mas sadia" dos martinfierristas ao reivindicar para Buenos Aires o papel de "meridiano intelectual", apesar de apontar as influências estrangeiras na literatura argentina e de reafirmar a postura da cidade como "uma grande capital" onde reverberava os ecos das linguagens advindas das vanguardas européias e, finalmente, da importância da geração modernista argentina na busca por uma identidade nacional, especialmente na questão da língua ${ }^{13}$.

É esta a cidade de Buenos Aires que serviu de cenário para o florescente mercado de bens culturais que surgiu na primeira metade do século $\mathrm{XX}$, com a formação de grupos de intelectuais e seus periódicos literários, de casas editoras, de cafés e de livrarias que serviram como lócus de sociabilidade intelectual e ajudaram a construir uma imagem de Buenos Aires como uma ilha européia na América do Sul.

O estudo de Patrícia Artundo sob o título Mário de Andrade e a Argentina: um pais e sua produção cultural como espaço de reflexão demonstrou que grupos de exilados propiciaram o aparecimento de muitos periódicos culturais e o incremento do mercado editorial de língua espanhola ${ }^{14}$. Isso pode ser corroborado com algumas missivas que mostram a circulação de idéias entre a intelectualidade da região, o que se depreende de algumas correspondências entre Mário de Andrade e Portinari, Mário de Andrade e Newton Freitas, Newton Freitas e Portinari, Guillermo de Torre e Portinari, Jorge Romero Brest e Portinari, Rafael Alberti e Portinari.

As correspondências revelam que o mercado editorial começava a se voltar para o campo artístico, com publicaçóes sobre artistas e suas obras, crítica de arte e literatura, além de mostrar que existia uma aproximação entre alguns segmentos da intelectualidade dos dois países, Brasil e Argentina. O que se evidencia são "políticas da amizade", na feliz expressão de Raul Antélo ${ }^{15}$. Tais políticas encontram em alguns exilados elos para a execução de alguns projetos comuns, como Newton Freitas, que foi uma "ponte sobre o pântano" entre Mário de Andrade e o meio intelectual portenho, embora o escritor/editor diga o contrário:

Minha amizade com Mário de Andrade foi uma espécie de amor à primeira vista. [...] Ele lia tudo, mas tudo mesmo, acompanhava minhas atividades literárias em Buenos Aires. Na verdade, Mário sabia tanto de literatura Argentina sem nunca ter estado em Buenos Aires, o estava de tal forma ligado aos escritores da "avant-garde" portenha da sua geração, que eu não 
tive sequer o trabalho de esclarecê-lo a respeito do que se passava na cidade que me recebera como emigrado do Estado Novo, sem um centavo no bolso, e me adotara definitivamente, dando-me a oportunidade de realizar junto à imprensa do Rio da Prata um trabalho de aproximação literária e artística entre o Brasil e a Argentina. [...] A época favorecia esta eclosão literária portenha. A guerra da Espanha terminada, a guerra da Europa começada, Buenos Aires estava cheia de escritores, ensaístas, pintores, músicos, vindos, quer da Espanha, quer da França - cortada em duas partes. Era a época em que Don Manuel de Falla, Ortega y Gasset, Ramón Gómez de la Serna, Rafael Alberti, Francisco Ayala, o pintor Colmeiro, Lorenzo Varela e tantos outros espanhóis exilados, fugidos de uma Espanha ensangüentada, misturavam-se com exilados de todas as partes.[...] Foi a época de ouro da cultura Argentina. No centro de todos, como pólo único: Vitória Ocampo ${ }^{16}$.

Esta efervescência cultural na mítica capital portenha de que fala Newton Freitas incluía a participação dos exilados. As correspondências apontam para o incremento do mercado de bens culturais, como a valorização da crítica de arte, que pode ser constatada numa carta de Jorge Romero Brest para Portinari, na qual fala do recebimento do folheto editado sobre o painel Tiradentes ${ }^{17}$, quando foi exposto no Museu de Arte Moderna de São Paulo em setembro de 1949, sobre o qual pretendia tecer comentários na sua revista Ver y Estimar. Então, Brest pede ao pintor

Usted habrá visto que hay en la revista una sección titulada El artista frente al mundo. Me gustaría que Usted escribiera algunas cuartillas expresando de qué manera contempla el panorama del mundo, en todos sus aspectos y en relación con la pintura, qué es lo que se propone y qué es lo que vaticina. $\mathrm{Si}$ usted me enviara esas cuartillas, seria la ocasión para que yo publicara a mi vez un corto ensayo sobre las pinturas murales suyas que conocí en Rio y sobre esta obra nueva que se acaba de inaugurar. Mucho le agradeceré también que junto con el artículo me mande algunas buenas fotografias de Tiradentes para que la reproducción sea nítida ${ }^{18}$.

As editoras portenhas estavam direcionando-se para um novo filão das artes - literatura e artes visuais -, como se depreende do pedido do editor Newton Freitas para Portinari, sobre a organização de um dicionário biográfico que se denominaria "Quem é quem no Brasil" para o ano de 1944, no qual publicaria o resumo da vida das mais importantes perso- 
nalidades do Brasil contemporâneo. Para isso, precisava que o pintor preenchesse um formulário com seus dados pessoais e da sua produção pictórica. Segundo o editor, a primeira edição seria publicada em um volume especial encadernado, com 700 páginas aproximadamente. Também fez o mesmo pedido por carta para Mário de Andrade, que responde positivamente ao pedido e se compromete a distribuir os prospectos para 40 músicos, mas adverte "Aliás já principiei. Adjunto no verso de cada prospecto uma palavrinha minha, que você mesmo verá pelos que receber de volta, mas você já sabe esta incúria dos brasileiros em responder cartas e coisas deste gênero" 19 .

O gênero biográfico de destacar personalidades de diversos segmentos da sociedade - escritores, poetas, artistas plásticos, jornalistas, musicistas, entre outros - é similar ao modelo aplicado nos Estados Unidos, conforme atesta Mário de Andrade em carta para Newton Freitas.

O mercado editorial adquiriu uma projeção importante na divulgação de autores e livros que passaram a fazer parte da história literária, como as coleções lançadas pela Editorial Losada, em 1938, que foram confiadas pelo seu fundador Gonzalo Losada, às figuras-chaves da cultura ibero-americana, como Pedro Henríquez de Ureña, Francisco Romero e Guillermo de Torre. Entretanto, a necessidade de "publicação de obras sobre artes plásticas" foi o mote dado por Jorge Romero Brest em artigo publicado em Argentina Libre, sob o título No se editan libros sobre Artes Plásticas, no qual chama a atenção para o crescente interesse do público pelas artes plásticas, especialmente as tão propaladas "manifestações modernas" 20 .

A Editorial Losada segue a orientação de Romero Brest, na série argentina da Colección Monografias de Arte, que teve seus três primeiros volumes lançados no primeiro semestre de 1941. O primeiro volume sobre a obra do retratista e costumbrista Prilidiano Pueyrredón (1823-1873) foi escrito por Romero Brest; o segundo volume dedicado à obra do artista plástico, cenógrafo e tapeceiro Horacio Butler (1897-1983); e o terceiro à obra do artista plástico Lino Spilimbergo (1896-1964). Também, a série americana seria composta pelos muralistas mexicanos José Clemente Orozco e Diego Rivera e pelo brasileiro Cândido Portinari.

A monografia sobre Portinari que foi confiada a Mário de Andrade partiu de um convite de Guillermo de Torre, mas que deve ter sido sugerida 
por Newton Freitas, conforme indica uma missiva do escritor para o editor, na qual dissera "Recebi da Editorial Losada, estou vendo a mão de você nisso, um convite para escrever um livro sobre Portinari, daquelas monografias ótimas que essa casa faz". Também, Mário de Andrade escreve para Portinari contando sobre

[...] o convite para escrever uma monografia de umas 8 mil palavras sobre você, que terá mais 32 reproduções fotográficas de quadros de você e mais uma reprodução em cores. Estou com vontade de aceitar, mas primeiro vou mandar perguntar a eles como farão a reprodução em cores. Si você souber, mande dizer os quadros de você que estarão por acaso em Buenos Aires e quais os seus possuidores. Talvez eles possam reproduzir um desses ${ }^{21}$.

A monografia sobre Portinari não foi entregue ao editor até a morte de Mário de Andrade em fevereiro de 1945, por diversos motivos alegados pelo escritor, conforme revelam suas cartas para diversos interlocutores. A partir daí, a Editorial Losada, em ofícios assinados por Guillermo de Torre, comunica a Portinari que, conforme indicação de Newton Freitas, de comum acordo com o pintor, o autor da "monografia pictórica" sobre sua obra seria Santa Rosa e pedia que cuidasse pessoalmente de remeter à editora 32 reproduçôes em preto-e-branco, além de um desenho para a capa, uma lâmina em cores para o frontispício e se dispunha em Buenos Aires de um quadro seu para fazer a gravação em cores. Apesar de todos os esforços, a monografia sobre Portinari pela Editorial Losada nunca saiu ${ }^{22}$.

A atuação dos brasileiros Lídia Besouchet e Newton Freitas no meio cultural portenho está relacionada à atividade desempenhada na imprensa argentina, especialmente nas revistas culturais e nas inúmeras publicações que surgiram no mercado editorial, além de produzir artigos divulgando a produção literária do Brasil, como na recompilação Diez Escritores del Brasil (1939), que aparecerá em nova edição revista e ampliada sob o título Literatura del Brasil (1946). Mário de Andrade publica um artigo sob o título "Vida literária: Literatura", no qual chama a atenção para essa produção:

[...] E ainda quero continuar na Argentina para noticiar um livro que nos interessa particularmente. A Literatura brasileira vai aos poucos aguçando o interesse das outras nações hispano-americanas. Recentemente, um editor argentino, observando essa tendência mais ou menos generalizada por toda a América espanhola, veio ao Brasil com o fito de estabelecer o inter- 
câmbio de traduções e carrear para a sua casa comercial as edições brasileiras, diz - que muito procuradas em Buenos Aires. Homem de percepção muito fina, ele reconhecia a excelência da ficção brasileira contemporânea, não só pelo valor pessoal de muitos de seus autores, como pela sua força de caráter e originalidade nacional. [...] Embora com ótimas exceçōes, ele dizia, a literatura de certos países hispano-americanos sofre em principal de um certo internacionalismo, excessivamente presa a modelos europeus. [...] mas o tratamento brasileiro desses problemas vinha tingido do maior vigor diferencial. E isto que aguçava o interesse no estrangeiro. Deve ter sido mais ou menos esta a opinião que orientou a Sra. Lídia Besouchet e o Sr. Newton Freitas na série de estudos sobre literatura brasileira publicados nos jornais argentinos e faz pouco reunidos no volume dos Diez Escritores del Brasil (ed. Gleizer, Buenos Aires, 1940) ${ }^{23}$.

Interessante ressaltar que a escritora Lídia Besouchet aparece num verbete da Enciclopédia da Literatura Brasileira como biógrafa, romancista e ensaísta. Entre seus romances destacam-se "Condição da mulher" (1947), "O Mestiço" (1947) e "Cidade Exílio" (1961), além de ter publicado o volume "Correspondência política de Mauá no Rio da Prata - 1850-1855" (1943), que compôs a Coleção Brasiliana, da Companhia Editora Nacional. Newton Freitas também aparece como teatrólogo, ensaísta, romancista e jornalista. $\mathrm{Na}$ capital portenha, desempenhou papel de editor e publicou os livros Contos y Lendas Brasileñas (traduzido por Lorenzo Varela, em 1943) e Ensayos Americanos - crítica literária (traduzido por Luis Baudizzone, em 1942) ${ }^{24}$.

Sobre este último livro, Mário de Andrade dedicou uma carta com um longo comentário e escreveu um texto para o prólogo à edição brasileira dos "Ensaios Americanos" (1945), no qual aproveitou um artigo sob o título "Um Sul-Americano" para elogiar o escritor e a "originalidade mais sutil destes ensaios de crítica", mas discorre com propriedade sobre a "noção pecaminosa do bom vizinho" e as práticas da boa-vizinhança, na qual situa o escritor:

Esse fandango, Newton Freitas não sabe dançar. Se perseguimos o caminho do seu pensamento e de sua obra vemos que nada existe de doutrinário na vida deste sulamericano. Sulamericano....O próprio Newton Freitas, no seu estudo sobre Luiz Alberto Sánchez, se impacienta deste nosso isolamento na América Latina, aventando de maneira sutil e inesperada o problema das 
influências. É dramática a situação humana do Brasil na Sulamérica.[...] Newton Freitas é o sulamericano sem sumário ${ }^{25}$.

Se no campo literário as queixas se avolumam quanto ao pouco conhecimento de autores e livros dos dois lados da América do Sul, a de língua lusófona e hispanófona, no campo das artes visuais, a tão propalada integração sul-americana parece mais complexa, daí o papel fundamental da crítica de arte de Jorge Romero Brest e da circulação das revistas culturais na região, o que vem corroborar com a tese de que

As revistas são classicamente lugares de sociabilidade intelectual. Lugares de articulação de pessoas e idéias que precisam de suportes materiais e simbólicos para fazer circular seus projetos, sem o que eles perdem significado. Os ganhos, portanto, são de ordem não instrumental, estando fora da lógica dos cálculos de custos e benefícios materiais, e inserindo-se no universo das paixões, crenças e vaidades intelectuais, como nos lembra Mário de Andrade ${ }^{26}$.

A partir da crítica de arte nos periódicos e/ou hebdomadários é possível mapear quais os artistas plásticos e gráficos que pontificavam nos países da América do Sul. Aqui, cabe uma ressalva: na década de 1940, Portinari era um artista consagrado internacionalmente, com participação em inúmeras exposições individuais e coletivas, além de premiado pelo Carnegie Institute com o óleo sobre tela "Café" (1934). Com toda essa exposição, as suas obras passaram a figurar em museus e coleções particulares da Europa e dos Estados Unidos ${ }^{27}$.

Efetivamente, é nos anos 40 que Portinari se integra ao circuito platino: quando participou da mostra coletiva Veinte artistas brasileños, realizada no Museu de Belas-Artes de La Plata, no Museu Nacional de Belas Artes, em Buenos Aires, e no Salón da Comisión Municipal de Cultura, em Montevidéu, organizada pelo escritor Marques Rebelo, em 1945, sob os auspícios do Ministério da Educação e do Serviço de Cooperação Intelectual do Ministério das Relaçôes Exteriores do Brasil, da qual resultou numa análise acurada do panorama artístico brasileiro por Jorge Romero Brest sob o título La Pintura Brasileña Contemporánea, editada pela Poseidon,de Buenos Aires, no mesmo ano; quando realizou exposições individuais no Salón Peuser e na Sociedad Hebraica Argentina, ambas em Buenos Aires,em julho de 1947 e em junho de 1948, respectivamente; 
quando proferiu uma conferência em Buenos Aires publicada sob o título Sentido Social del Arte, pelo Centro de Estudantes de Belas-Artes em 1947; quando participou da mostra coletiva 35 Litografias Brasileñas, em Montevidéu, em dezembro de 1946, e realizou uma exposição individual Portinari en Montevidéo, patrocinada pela Comisión Nacional de Bellas Artes, em setembro de 1947, além de realizar a exposição individual Exposición de Monotipos y Dibujos, na Galeria Este, em Punta del Este, no Uruguai, em março de 1949.

Na outra margem do Rio da Prata - estão os orientais, como os argentinos chamavam os uruguaios - é que estão os missivistas de Portinari, em Montevidéu: o pintor Carlos Washington Aliseris e o poeta, escritor e crítico de arte Cipriano Santiago Vitureira; e na cidade de Salto, o poeta e escritor Enrique Manuel Amorim.

O caminho epistolar trilhado por Aliseris desvela o universo deste pintor uruguaio. Das suas missivas é possível apreender a linguagem, o vocabulário e também das marcas deixadas pelos desenhos que sinalizam para a afetividade e para a proximidade física da relação que está em jogo ${ }^{28}$. Além da aproximação com Portinari, manteve contato com o meio artístico brasileiro, inclusive esteve no Brasil no segundo semestre de 1934: fixou paisagens cariocas em óleos e guaches; em São Paulo apresentou uma exposição individual patrocinada pela Sociedade Pró-Arte Moderna (SPAM) de outubro a novembro de 1934; enviou quatro trabalhos para o II Salão Paulista de Belas Artes de 1935; o Conselho de Orientação Artística adquiriu para a Pinacoteca do Estado de São Paulo seu óleo La joven del laurel; nesta temporada conheceu Mário de Andrade, a quem retratou e o presenteou com três desenhos de 1934 (nu feminino) e um guache sobre papel "Morangos", da sua filha Raquel Aliseris Bernadá ${ }^{29}$.

Os platinos desempenharam um papel importante na divulgação da produção portinariana, como se depreende dos artigos e das críticas de arte que se encontram na imprensa internacional, como na Clarté, de Bruxelas, de junho de 1939, em que Aliseris publicou Portinari grand peintre du Brésil, com ilustrações da obra do pintor, no qual discorre sobre os retratos, as paisagens, as composições, a grande criação mural, como os afrescos do Ministério da Educação, e procurou demonstrar que o sentido social da obra do pintor está relacionado à luta do homem pela terra. Completou o seu raciocínio com a frase "C'est que Portinari est avant tout un artiste, un 
être sensible à tout ce qui est legitime et permanent, à tout ce qui doit subsister: la representation de l'homme dans son aspect fondamental, - le travail" 30 .

Outros integrantes do círculo de amizades de Portinari ou das "políticas da amizade" publicaram artigos sobre o pintor e a sua obra em periódicos de várias partes da América hispanófona, com destaque para uma entrevista concedida à escritora argentina María Rosa Oliver publicada no número 152, de julho de 1947, da Revista Sur, dirigida por Vitória Ocampo, sob o título Conversando con Cándido Portinari; Candido Portinari: El gran pintor representativo del Brasil, por Nicolás Guillén, publicado em El Nacional, de Caracas, de 20 de outubro de 1949; De donde viene y hacia donde va Candido Portinari, por Enrique Amorim, publicado no semanário Orientación, órgão do Partido Comunista, na edição número 402, de Buenos Aires, de 30 de julho de 1947; Portinari, pintor de nuestro tiempo, por Córdova Iturburu, publicado em La Hora, de Buenos Aires, na edição de 26 de julho de 1947; Candido Portinari en Montevidéo, por Cipriano Santiago Vitureira, publicado no Boletim do Instituto Cultural UruguayoBrasileño, em Montevidéo, em agosto de 1948. Ao que parece, todos os periódicos da região platina daquela época repercutiram a temporada do pintor na região e o sentido social que impregnava a sua obra num mundo em transformação, desde a grande imprensa, como La Prensa, El Clarín e La Nación, até periódicos com circulação mais restrita, como Qué, El Lider, Critica, entre outros.

O impacto que a obra portinariana da sua "fase social" causou no ambiente portenho pode ser constatado nas lembranças de um atento observador:

Mas, voltando à exposição de 1947, eu me lembro ainda, 45 anos depois (!), do sucesso extraordinário que significou. Em qualquer reunião de estudantes se falava da exposição de Portinari, de seus meninos e mulheres chorando, impregnados de um expressionismo impactante, que nos fazia conhecer mais de perto uma parte da realidade brasileira. Ao mesmo tempo deleitava-nos com seu desenho tão particular e seu rico sentido das cores. Ainda estamos vendo aqueles pés, aquelas mãos, aqueles abraços descomunais e os olhos transidos de dor e tristeza. [...] a exposição realizada em Buenos Aires [Salón Peuser], em 1947, e que foi um marco para a cultura argentina ${ }^{3}$. 
Entre os críticos da região platina que passaram a analisar a produção artística do pintor de Brodósqui, destaca-se Cipriano Vitureira, que escreveu Sentido humanista de la pintura brasileña contemporanea, que compôs o segundo volume da coleção "Monografias Amizade", publicada pela Asociación Uruguaya de Profesores de Idioma Portugués, em 1947, que foi o resultado da mostra 35 Litografias Brasileñas, no qual discorreu sobre as tendências das artes visuais no Brasil, desde o consagrado Portinari ao novato Iberê Camargo, e publicou também Portinari en Montevidéo, pelas Ediciones Alfar, em 1949.

$\mathrm{Na}$ formação dessa rede de sociabilidade intelectual, os projetos estéticos e políticos atravessaram várias vezes o Atlântico, como na "Campanha da Paz", cuja bandeira foi desfraldada pelo Partido Comunista durante a guerra fria, o que levou ao engajamento de intelectuais e artistas que militavam nas hostes de esquerda, conforme se depreende do cartão postal cuja ilustração é de uma pomba - identificada como símbolo da paz -, desenhada por Picasso, enviado de Paris para Portinari por Pablo Neruda, Jorge Amado, Nicolás Guillén e Alfredo Varela. Estes militantes estavam na capital francesa para participar do Congrès Mondial des Artisans de la Paix, que se realizava na Salle Pleyel, entre os dias 20 e 23 de abril de $1949^{32}$.

À medida que os anos passam, os laços de amizade se estreitam e apareceram novos interlocutores, como o crítico e editor italiano Giuseppe Eugenio Luraghi (1905-1992), que conhece Portinari por intermédio de Rafael Alberti, o qual tinha publicado um livro de poesias escolhidas e traduzidas em língua italiana. Após uma visita ao pintor, torna-se um fiel admirador da arte portinariana, conforme declarou num artigo sob o título Candido Portinari: um Michelangelo brasiliano, para a revista Rotary, de Milão, de novembro de 1983, e o compara a um dos maiores artistas do renascimento, Michelangelo Buonarroti (1475-1564), o qual foi um exímio pintor, com profundo conhecimento do ofício: uma sólida técnica de pintura de afrescos e o domínio da arte do desenho. Além disso, a editora ILTE, de Turim, publica dois livros sobre a obra do pintor, como Disegni di Portinari, em 1955, com introdução de Luraghi, em quatro línguas, reproduzindo 112 obras do artista, e Brasil, dipinti di Portinari, em 1960, organizado e prefaciado por Luraghi.

Das políticas das amizades consolidadas através de projetos estéticos e políticos, Jorge Romero Brest se tornou conhecido e respeitado no cir- 
cuito das artes visuais no Brasil. Inclusive, consta do catálogo da "Exposição Portinari", realizada no Museu de Arte Moderna (MAM), do Rio de Janeiro, em abril de 1953, um comentário de Brest sobre a obra do pintor, o mesmo que publicou em Ver y Estimar, em julho de 1948, e participou do júri da VI Bienal de São Paulo, em 1961, na qual foi premiada a pintora portuguesa Maria Helena Vieira da Silva. Portinari deixou para a posteridade, em La Gallarda, a residência dos Alberti [o poeta Rafael, a escritora Maria Teresa León e a filha do casal Aytana], no balneário uruguaio de Punta del Este, uma pintura mural "Mulher e Criança" 33 na parede da sala de jantar da casa e os desenhos acima mencionados. Também, Cipriano Vitureira e Beba, sua companheira, foram presenteados com os desenhos "Homem Chorando", "Mulher" e "Menina"34, ilustrando os dois últimos o poema Mujer e La Niña, que compóem o livro Portinari en Montevidéo. Além do mais, a obra portinariana continua a ser fruída em museus e coleçóes privadas na região platina.

O ano de 1947 representou simbolicamente a integração de Portinari ao círculo da intelectualidade platina, apesar da troca de correspondências com Aliseris indicar o ano de 1934 como o início de uma interlocução sobre o campo artístico sul-americano. Entretanto, a efervescência no campo político europeu e sul-americano predispôs engajamentos políticos, nos quais a intelectualidade do subcontinente não ficou alheia e acorreu para uma das margens do Rio da Prata, a mítica cidade de Buenos Aires. Daí, a permanência de Portinari em Montevidéu, o que possibilitou o seu deslocamento pela região e resultou numa interessante produção artística, que compreende desde o retrato do poeta cubano Nicolás Guillén, um óleo sobre tela, pintado em 1947, em Buenos Aires, que figurou na exposição do Salón Peuser, passando por retratos de senhoras da sociedade argentina, além de desenhos, monotipos, óleos que cobrem uma etapa significativa da sua vida que conjugava arte e política.

Aqui cabe destacar que o discurso de Portinari expresso na conferência Sentido Social del Arte e as imagens da fase social - com retirantes, homens e mulheres chorando, meninos de Brodósqui, crianças mortas se imbricam e expressam as angústias daquela geração que viveu a Guerra Civil Espanhola, o Franquismo, a Segunda Guerra Mundial, o Estado Novo no Brasil e estava vislumbrando um longo governo peronista que fora alçado ao poder pelo golpe militar do Grupo de Oficiales Unidos (GOU), em 1943. 
Apesar da capital portenha figurar como um centro cultural arrojado e inovador para os padrões da América do Sul, com o tão propalado cosmopolitismo e com os seus movimentos literários e artísticos, a intelectualidade que vivia na região platina continuava a ver Paris como o "meridiano de Greenwich", ou a capital da República Mundial das Letras, como pode ser constatado pela análise de Pascale Casanova ${ }^{35}$. Tal constatação pode ser aferida na opinião de alguns missivistas. Alberti menciona a existência "del grupo hispano de Paris", e Enrique Amorim sentenciou "Tengo una terrible nostalgia de Paris, de Europa. No me gusta, en general, la gente de estos climas. A pesar de los inconvenientes, áquello es una vida superior, más adecuada a lo que yo siento. Aún en el trabajo por la Paz" ${ }^{36}$.

Naquele momento, Buenos Aires, como um pólo de concentração de exilados de várias partes das Américas e da Europa, começa a perder sua aura de sacralidade do ponto de vista da estabilidade política e das condiçôes de liberdade. Além do mais, a condição de modernidade periférica passa a ser constatada em diversas missivas. Alguns interlocutores apontam que o destino de alguns exilados seria a França e deixam entrever um desconforto com a situação política dos dois países, premidos entre a Argentina com Juan Perón e a Espanha com o General Franco. Alberti, em carta de outubro de 1948, faz um comovido desabafo para Portinari:

Poco a poco, algunos españoles de nuestra emigración se van volviendo a Europa, a Francia sobre todo. Yo me iria también, pero a España. Mas como esto por ahora es imposible, me aguanto aquí y trabajo. Trabajo mucho, más por desesperación que por entusiasmo. Me alegra infinito saber que estás pintando otro gran mural. Tu tienes suerte. Todavía te respetan. ¡ Ojalá no pierdas nunca tu país! Pero aunque lo perdieras, un pintor como tú, de no venirse abajo el mundo entero, siempre tendría adonde ir. La pintura no necesita traducción, etc ${ }^{37}$.

Alguns anos depois, em junho de 1951, o escritor Enrique Amorim reafirma a situação incômoda que Alberti estava vivendo, inclusive com a proibição de sair de Buenos Aires:

El pobre Rafael no podrá moverse de Buenos Aires, ni para venir a ver su casa en Punta del Este. No dejan salir a nadie sin certificado de buena conducta y sin pasaporte De aqui va poca gente a Buenos Aires por las 
trabas que ponen. Cada dia se cierran mas puertas. Hasta que estalle lo que ya resulta casi inevitable. Será terrible, pero se lo merecen... ${ }^{38}$.

O que alimentava essa rede de sociabilidade intelectual eram as correspondências entre diversos interlocutores do mundo cultural ibero-americano - poetas, escritores, críticos de arte, artistas plásticos e gráficos -, numa época de escassos recursos de comunicação, como afirmou laconicamente Alberti: "nos queda el camino epistolar..."

O século XX foi considerado o "século dos intelectuais", os quais foram movidos pela paixão política, cujo percurso levou à militância e ao exílio, apesar de o exílio ser visto por Edward Said como "um dos destinos mais tristes" do intelectual engajado, como foi o caso de Rafael Alberti, Cândido Portinari, Jorge Amado, Guillermo de Torre, Newton Freitas, Lídia Besouchet, entre muitos outros ${ }^{39}$.

O poder do intelectual exilado foi significativo no exterior, no qual se beneficiava das redes de apoio, como as internacionais comunistas, as internacionais liberais, os partidos políticos, os sindicatos etc. No caso especial do campo cultural ibero-americano, cada qual com o seu ofício conseguiu dar visibilidade às mazelas políticas do seu país de origem e formar uma opinião pública internacional a respeito das ditaduras que dominavam a península ibérica - Salazarismo e Franquismo - durante muitas décadas ${ }^{40}$. Além disso, alguns exilados sinalizaram para os destinos do peronismo e para as contradições do governo Dutra, no Brasil.

Também, conseguiram vislumbrar para o campo cultural discussóes como a introdução das novas linguagens advindas das vanguardas européias e a preocupação social na arte, conforme conferência proferida por Portinari em Buenos Aires, sob o título Sentido Social del Arte, em 1947, que transmite a idéia da importância dos murais com finalidade educativa, bem como que a pintura social deveria dirigir-se às massas. $\mathrm{O}$ teor da conferência aponta para um Portinari “educador”, que mostra a imbricação entre a pintura mural e a arte social, porque "o muro pertence à coletividade" e a pintura mural "conta uma história", interessando a um maior número de pessoas, o que levaria a obter dois resultados: a educação plástica e a educação coletiva. Daí a importância do "pintor social", que, para Portinari, seria "o intérprete do povo, o mensageiro dos seus sentimentos" e "aquele que deseja a paz, a justiça e a liberdade" ${ }^{4}$. 
Imbuídos desses ideais de solidariedade, o mundo cultural ibero-americano alimentou uma rede de sociabilidade intelectual que se formou através da militância de esquerda, principalmente das hostes do Partido Comunista de diversos países, o que leva à constatação de que esta geração de artistas e intelectuais iluminou o cenário cultural com discussóes que perpassaram as fronteiras nacionais, como, por exemplo, Portinari e seus interlocutores que fizeram das práticas de escrita - cartas, poesias, crítica de arte, textos jornalísticos - um exercício sobre o campo político e cultural dos dois continentes, Europa e América.

Aqui, as cartas pessoais foram entendidas como "objeto cultural", que permitiram desvelar o significado do pintor Portinari e o sentido da sua obra no afã de propagar o caráter público da obra de arte, a tragédia social brasileira com os seus dramas humanos, as mazelas do mundo com a guerra e o seu engajamento na campanha da paz. O exílio platino estreitou laços de amizades e propiciou um maior conhecimento da arte e das tendências artísticas existentes nas margens do Rio da Prata. Daí nasceram estas palavras de Alberti dedicadas ao pintor e a poesia a ele dedicada:

Pintamos horrores, Portinari, escribimos horrores, amigo. En nuestros ojos, aún apenas abiertos, una mano de niebla exprimió lo terrible. Noches crueles, dias crueles: claroscuro de lo espantoso. La luz hiende como una espada. La sombra nos inunda hasta ahogarnos. Y, sin embargo, sigue saliendo la luna, las olas estivales se dilatan tranquilas, y en los jardines el vaho de las flores continúa embriagándonos como tán sólo puede hacerlo el vaho de las flores. ¿ Pero qué alguien en medio nos arrojó estos monstruos? ¿Qué alguien se afana, se desvive, peleando con furia por alzarlos, moverlos, sostenerlos? ¿Qué alguien le carga el vientre a esta torturadora pesadilla que nos asedia, nos estruja, nos manda, nos exige? Aquí está, aquí llega como recién nacido de abultado frontal y pupilas extrávicas; aquí irrumpe como desmedrados y flojos pechos maternales, presos en las ancías heladas de la muerte; aquí estalla como llanto de piedras; aquí azota como bandada vagabunda de adefesios lisiados, cojitrancos de pellejos vacíos, desvelados de la miseria, aparecidos del hambre. Y nuestro solo pensamiento sería el de correr, huir, no mirar, defendernos. Porque allá, lo sabemos, se atiranta, llamándonos, lo azul, el fresco albor de la mañana, el contorno caliente de la arena, y a la orilla del río, todavía, llovidos los cabellos por la espalda, una posible náyade desnuda. 
Flores en la alameda, enamoradas A la luna, sin miedo, de la cita. ¿Pero quién de las flores

hace surgir de pronto rojas puntas de espadas, quién de la luna dinamita?

Tierra de espanto.

Tierra de estertores ${ }^{42}$.

\section{Notas}

${ }^{2}$ GOMES, Ângela de Castro. "Escrita de si, escrita da História: a título de prólogo". In: (Org.). Escrita de si, escrita da História. Rio de Janeiro: Ed. FGV, 2004. p. 19.

${ }^{3}$ NERUDA, Pablo. Confesso que vivi: memórias. 26. ed. Rio de Janeiro: Bertrand Brasil, 2003. p. 163-164.

Trata-se do principal poeta e dramaturgo da Revolução Russa de 1917: Vladimir Mayakovsky (1893-1930) foi aluno da MUZhVZ - Academia e Faculdade Moscovita de Pintura, Escultura e Arquitetura; pertenceu ao grupo da LEF - Front de Esquerda das Artes com o pintor, designer e fotógrafo Alexander Rodchenko e o crítico Osip Brik; integrou o primeiro grupo de poetas futuristas russos "Gileya"; junto com Kasimir Malevich criou posters de propaganda política, os chamados "Lubik"; e manteve um escritório de design com Rodchenko, o "Ad Designers".

${ }^{4}$ FABRIS, Annateresa. "A militância política". In: . Cândido Portinari. São Paulo: EDUSP, 1996. p. 141-150. (Col. Artistas Brasileiros,4)

${ }^{5}$ Carta de Rafael Alberti a Cândido Portinari, datada de Buenos Aires, 14 de agosto de 1948. CO-62/Projeto Portinari. Na casa de Rafael Alberti, localizada na calle Las Heras, ${ }^{\circ}$ 3783, em Buenos Aires, pode ser comprovada a existência de dois desenhos: "Homem Chorando", de 1947, desenho a crayon sobre papel, medindo 35 x 24,5 cm, datado de Montevidéo, Uruguay, assinado e datado na dedicatória na metade inferior à direita "Para o grandíssimo poeta Rafael com o abraço amigo de Portinari 1947" e "Cabeça de Menino", de 1947, desenho a crayon sobre papel, medindo 37 x $27 \mathrm{~cm}$. Aproximadamente, datado de Montevidéo, Uruguay, assinado e datado na dedicatória na metade inferior à direita "Para os amigos: Maria Thereza e Rafael com a maior admiração de Portinari 1947". In: PORTINARI, João Cândido et allii. Catálogo Raisonné. Rio de Janeiro: Projeto Portinari, 2004. v. III (1944-1955). P. 205.

${ }^{6}$ BREST, Jorge Romero. "Alabanza de Portinari”. In: Ver y Estimar. Buenos Aires, v. 1, n ${ }^{\circ}$ 4, julio de 1948.

7 SARLO, Beatriz. "Modernidad y mezcla cultural. El caso de Buenos Aires". In: BELLUZZO, Ana Maria de Moraes (Org.). Modernidade: vanguardas artísticas na América Latina. São Paulo: Memorial da América Latina/UNESP, 1990. p. 32-33. 
${ }^{8}$ FABRIS, Annateresa (Org.). Portinari, amico mio: Cartas de Mário de Andrade a Cândido Portinari. Campinas/Rio de Janeiro: Mercado de Letras/autores Associados/Projeto Portinari, 1995.160 p. il.

${ }^{9}$ FREITAS, Newton. Correspondência de Mário de Andrade a Newton Freitas. In: Revista do Instituto de Estudos Brasileiros. São Paulo: IEB/USP, 1975, no 17, p. 91-120.

${ }^{10}$ Sobre o ultraísmo, vide os estudos de: ANTELO, Raúl. Na Ilha de Marapatá (Mário de Andrade lê os hispano-americanos). São Paulo/Brasília: HUCITEC/INL, 1986. p. 17-24; KERN, Maria Lúcia Bastos. Arte Argentina: tradição e modernidade. Porto Alegre: EDIPUCRS, 1996. p. 125-139 (Col. História, 9). Os periódicos que divulgaram o ultraísmo são os seguintes: Cervantes - Revista hispano-americana, com uma primeira fase não ultraísta, a partir de janeiro de 1916, sob a direção de Villaespesa, Urbina e Ingenieros, com a mudança de direção em janeiro de 1919; Rafael Cansino-Asséns publica apenas poesia ultra de Gerardo Diego, Vicente Huidobro, Juan Larrea e Guillermo de Torre; Cosmópolis, revista mensal ilustrada de Madrid, criada em janeiro de 1919, publicou alguns hispano-americanos, como Jorge Luís Borges, divulgador das estéticas de vanguarda européia, especialmente o expressionismo; Grécia (outubro de 1918 a novembro de 1920), que segue a estética modernista de Rubén Darío, somente a partir da edição de fevereiro de 1919 o periódico começa a sofrer transformaçóes e publica os poemas de Max Jacob de 1906, acompanhado do artigo La nueva literatura. Também aparecem textos de Apollinaire, Marinetti e novas propostas estéticas são apresentadas nos editoriais, além do Manifiesto Vertical de Guillermo de Torre como suplemento do último número; Ultra (janeiro de 1921 a março de 1922), que surge em Madrid com uma moderna apresentação gráfica da argentina Norah Borges (1901-1998), do uruguaio Rafael Barradas (18901929) e do polonês Wladyslaw Jahl (1886-1953), é nesse periódico que o escritor argentino Jorge Luís Borges (1899-1986) apresenta o manifesto Anatomia de mi Ultra, opondo os valores das líricas expressionista e futurista.

${ }^{11}$ KERN, op. cit., p. 46.

${ }^{12}$ Id., p. 47.

${ }^{13}$ ANDRADE, Mário de. "Literatura Modernista Argentina I". Diário Nacional, São Paulo, 22 de abril de 1928. In: RODRIGUEZ-MONEGAL, Emir. Mário de Andradel Borges: um diálogo dos anos 20. São Paulo: Perspectiva, 1978. p. 73-85. (Col. Elos, 27).

${ }^{14}$ ARTUNDO, Patrícia. Mário de Andrade e a Argentina: um país e sua produção cultural como espaço de reflexão. São Paulo: EDUSP/FAPESP, 2004. 223 p.

${ }^{15}$ ANTELO, Raúl. "Políticas da amizade e anamorfose do moderno". In:

Potências da imagem. Chapecó: Argos, 2004. p. 29-74.

${ }^{16}$ Vide: Apresentação e Notas de Newton Freitas. In: FREITAS, op. cit., p. 91-92.

${ }^{17} \mathrm{O}$ painel Tiradentes foi executado por Portinari sob encomenda de Francisco Inácio Peixoto para o Colégio de Cataguases, em Minas Gerais, projetado por Oscar Niemeyer, datado de 1948-1949, com a técnica têmpera sobre tela, medindo 309 x $1.767 \mathrm{~cm}$. O painel foi adquirido pelo Governo do Estado de São Paulo em 1975, ficou no Palácio dos Bandeirantes até 1989, quando foi transferido para o Salão de Atos do Memorial da 
América Latina, na cidade de São Paulo. Trata-se do Catálogo da Exposição do Mural Tiradentes de Cândido Portinari. São Paulo: MAM, 1949. 34 p. il., o qual contém uma longa descrição do painel indicando as personagens aludidas, um encarte fotográfico do painel em preto e branco, detalhes do painel, além de documentos históricos sobre a Inconfidência Mineira. Sobre este painel, vide: MILLIET, Maria Alice. "Da História ao mito: Cândido Portinari”. In: . Tiradentes: o corpo do herói. São Paulo: Martins Fontes, 2001. p. 221-253.

${ }^{18}$ Carta de Jorge Romero Brest a Cândido Portinari, datada de Buenos Aires, s. d. CO5217.1/Projeto Portinari.

${ }^{19}$ Carta de Newton Freitas a Cândido Portinari, datada de Buenos Aires, 25 de março de 1944. CO-1843/Projeto Portinari. Carta de Mário de Andrade a Newton Freitas, datada de São Paulo, 16 de abril de 1944 e Carta de Mário de Andrade a Newton Freitas, datada de São Paulo, 9 de junho de 1944. In: FREITAS, op. cit., p. 112-113.

${ }^{20}$ Vide citação do artigo de BREST, Jorge Romero. No se editán libros sobre Artes Plásticas. Argentina Libre, Buenos Aires, 21 marzo de 1940, no 3. p. 3 apud ARTUNDO, op. cit., p. 171-173.

${ }^{21}$ Carta de Mário de Andrade a Newton Freitas, datada de São Paulo, 9 de dezembro de 1942. In: FREITAS, op. cit., p. 103; Carta de Mário de Andrade a Cândido Portinari, datada de s.l., 3 de novembro de 1942. In: FABRIS, op. cit., p. 112.

22 Sobre as tratativas que nortearam a desistência de Mário de Andrade de fazer a monografia sobre Portinari para a Editorial Losada, vide: FABRIS, Annateresa. História de uma amizade. In: op. cit., p. 13-44, 112-113, 151-153; FREITAS, op. cit., p. 91-120; Carta de Guillermo de Torre a Cândido Portinari, datada de Buenos Aires, 12 de junho de 1945, CO-5555/Projeto Portinari; Carta de Guillermo de Torre a Cândido Portinari, datada de Buenos Aires, 3 de agosto de 1945, CO-5536/Projeto Portinari; Carta de Guillermo de Torre a Cândido Portinari, datada de Buenos Aires, 21 de agosto de 1945, CO-5537/Projeto Portinari; ANDRADE, Mário de. Cartas a Murilo Miranda, 1934/1945. Rio de Janeiro: Nova Fronteira, 1981. p. 132-133. Santa Rosa de que fala a correspondência de Guillermo de Torre é Tomás Santa Rosa Júnior (19091956), pintor, ilustrador, cenógrafo, crítico de arte e professor ativo no Rio de Janeiro.

${ }^{23}$ ANDRADE, Mário de. "Vida literária: literatura". Diário de Notícias, Rio de Janeiro, 26 de maio de 1940. apud ANTELO, Raúl. Na Ilha de Marapatá: Mário de Andrade lê os hispano-americanos, p. 194

${ }^{24}$ Cf. COUTINHO, Afrânio; GALANTE de Sousa, J.J. (Orgs.). Enciclopédia da Literatura Brasileira. 2. ed. São Paulo/Rio de Janeiro: Global/FBN/ABL, 2001. v. 1. p. 350 e 737.

${ }^{25}$ Carta de Mário de Andrade a Newton Freitas, datada de São Paulo, 31 de janeiro de 1943. In: FREITAS, op. cit., p. 105-106. O prólogo à edição brasileira dos Ensaios Americanos, publicado pelo editor Zélio Valverde, em 1945, encontra-se sob o título "Newton Freitas"; o artigo intitulado "Um sul-americano" foi publicado no "Diário de São Paulo", de 8 de janeiro de 1944. In: ANTELO, op. cit., p. 197-200. 
${ }^{26}$ GOMES, Ângela de Castro. Essa gente do Rio...Modernismo e Nacionalismo. Rio de Janeiro: Ed. FGV, 1999. p. 58.

${ }^{27}$ Portinari participou dos seguintes eventos no circuito das artes plásticas na Europa e nos Estados Unidos: desde 1935, quando participou da Exposição Internacional de Pintura patrocinada pelo Carnegie Institute, de Pittsburgh, na Pensilvânia, e ganhou a segunda menção honrosa com o "Café"; quando participou com nove obras da Exhibition of Modern Paintings, Drawings and Primitive African Sculpture from the Collection of Helena Rubinstein (1940), em Washington e New York; quando participou da Latin American Exhibition of Fine Arts (1940), no Riverside Museum, em New York; quando participou da mostra individual Portinari of Brazil (1940), no The Detroit Institute of Arts e posteriormente no Museum of Modern Art (MOMA), em New York; quando realizou uma mostra individual na Galerie Charpentier (1946), em Paris, cuja apresentação do catálogo é do crítico Jean Cassou e o prefácio de Germain Bazin; quando participou com a obra "Morro" da exposição de Art of the United Nations, no Instituto de Arte de Chicago; além de executar um conjunto mural para a Fundação Hispânica da Biblioteca do Congresso, em Washington.

${ }^{28}$ GOMES, Escrita de si, escrita da História, p. 21.

${ }^{29}$ Os desenhos de Carlos Washington Aliseris e o guache sobre papel de sua filha Raquel Aliseris Bernadá pertencem ao setor de Artes Plásticas da Coleção Mário de Andrade, que está no Instituto de Estudos Brasileiros da Universidade de São Paulo. Cf. BATISTA, Marta Rossetti; LIMA, Yone Soares de. Coleção Mário de Andrade: Artes Plásticas. 2. ed. São Paulo: IEB/USP, 1998. p. 241 e 293.

${ }^{30}$ ALISERIS, Carlos Washington. Portinari grand peintre du Brésil. Clarté, Bruxeles, juin 1939. p. 18-20.

${ }^{31}$ GIAMBIAGI, Mario. Uma lembrança de Portinari. Rio de Janeiro, 1992. p. 4. TX154.1.1/Projeto Portinari.

32 Carte Postale de Pablo Neruda, Nicolás Guillén, Jorge Amado e Alfredo Varela para Cândido Portinari, datado de Paris, 20 avril 1949. CO-3628/Projeto Portinari. Pablo Neruda registrou em suas memórias que depois de rever Picasso em Paris e exaltar quão magnânimo era o pintor, disse: "Na ocasião, celebrava-se em Paris um congresso da paz. Apareci em seus salóes no último momento, só para ler um dos meus poemas". In: NERUDA, op. cit., p. 221.

33 "Mulher e Criança”, pintura a têmpera e afresco sobre reboco, medindo $120 \times 82 \mathrm{~cm}$ (I) e $140 \times 102 \mathrm{~cm}$ (S). Obra assinada no canto inferior direito <<Portinari 1948>>, originalmente executada para decorar a parede da sala de jantar da casa do poeta Rafael Alberti, em Punta del Este, no Uruguay. A obra foi recortada da parede e colada em tela pelo restaurador Manoel Nigro, em 1982. In: PORTINARI, João Cândido et allii. Catálogo Raisonné. Rio de Janeiro: Projeto Portinari, 2004. v. III (1944-1955). P. 215.

34 "Menina", desenho a caneta-tinteiro sobre papel, medindo 23 x $20 \mathrm{~cm}$, datado de Montevidéu, Uruguai, 1948. Assinada e datada na dedicatória na metade inferior à direita "Para Vitureira e Beba com a amizade de Portinari Mont. 1948". "Homem Chorando", desenho 
a caneta-tinteiro sobre papel, medindo 28,5 x 21,5 cm, datado de Montevidéu, Uruguai, de 1947. Assinada e datada na metade inferior à direita "Para o amigo Vitureira com o abraço de Portinari Mont. set. 1947". O desenho "Menina" serviu como ilustração para o poema La Niña, do livro Portinari en Montevidéo, de Cipriano Santiago Vitureira. Também, a companheira de Vitureira, chamada Beba, ganhou "Mulher Chorando", desenho a caneta-tinteiro sobre papel, medindo 29,5 x 20,5 cm datado de Montevidéu, Uruguai, de 1948. Assinada e datada na dedicatória na metade inferior à direita: "Para Beba com a amizade e carinho do Portinari Montevidéo 1948”. Este desenho serviu de ilustração para o poema La Mujer compor o livro de Vitureira, Portinari en Montevidéo (Montevidéo: Ediciones Alfar, 1949.86 p. il.)

35 CASANOVA, Pascale. A República Mundial das Letras. São Paulo: Estação Liberdade, 2002.

${ }^{36}$ Carta de Rafael Alberti para Cândido Portinari, datada de Buenos Aires, 29 de octubre de 1949. CO-65/Projeto Portinari. Carta de Enrique Amorim para Cândido Portinari, datada de Montevidéo, 21 de mayo de 1952. CO-201/Projeto Portinari.

${ }^{37}$ Carta de Rafael Alberti para Cândido Portinari, datada de Buenos Aires, 22 de octubre de 1948. CO-66/Projeto Portinari.

${ }^{38}$ Carta de Enrique Amorim para Cândido Portinari, datada de Salto (Uruguai), 4 de junio de 1951. CO-202/Projeto Portinari.

39 Sobre o papel dos intelectuais no século XX, vide: WINOCK, Michel. O século dos intelectuais. Rio de Janeiro: Bertrand Brasil, 2000. O livro é dividido em três partes: "Os anos Barrès", "Os anos Gide" e "Os anos Sartre". SAID, Edward W. Representações do Intelectual: as Conferências Reith de 1993. São Paulo: Companhia das Letras, 2005. Sobre o exílio de Jorge Amado em Dobris, na Tchecoslováquia, vide: GATTAI, Zélia. Jardim de Inverno. 6. ed. Rio de Janeiro: Record, 1989.

40 BACHOUD, Andrée. "Intelectuais e franquismo". In: BASTOS, Elide Rugai; RIDENTI, Marcelo; ROLLAND, Denis (Orgs). Intelectuais: sociedade e politica. São Paulo: Cortez, 2003. p. 172-181.

${ }^{41}$ PORTINARI, Cândido. Sentido Social del Arte. Buenos Aires: CEBA, 1947. 22 p. il.

42 Texto escrito por Rafael Alberti para compor o catálogo da exposição de Portinari em Punta del Este, no Uruguai. TX-142/Projeto Portinari. A poesia $<<$ Portinari $>>$ está publicada na íntegra na obra de ALBERTI, Rafael. A la pintura: poema del color y la línea (1945-1976). Barcelona: Editorial Seix Barral, 1978. p. 189-192.

\section{Resumo}

O presente artigo visa mostrar uma rede de sociabilidade intelectual formada a partir das relaçôes entre o pintor Cândido Portinari (1903-1962) com o mundo cultural ibero-americano, especialmente com o poeta espanhol Rafael Alberti, com o critico de arte argentino Jorge Romero Brest e com os uruguaios, Carlos Washington Aliseris, 
pintor, Cipriano Santiago Vitureira, escritor e critico de arte, e Enrique Amorim, poeta e escritor, entre outros. Aqui, as correspondências foram analisadas como "objeto cultural", seguindo a trilha dos estudos desenvolvidos sob a perspectiva da história dos intelectuais segundo a tradição francesa. Tais missivas revelaram que para a cidade de Buenos Aires acorreu um significativo número de exilados de várias partes da Ibero-América e da Europa (com ênfase nos espanhóis), o que levou a cosmopolita capital portenha a figurar como um promissor mercado de bens culturais.

Palavras-chave: Portinari; epistolografia; campo cultural.

\section{Abstract}

This article wants to show a net of intelectual sociability to be a relationship between the painter Candido Portinari (1903-1962) and the ibero-american's culturafl world, specially with the uruguayans Carlos Washington Aliseris, painter, Cipriano Santiago Vitureira, writer, and Enrique Amorim, poetry, and others. Here, the letters was analised like "cultural object", in the way of the intelectual's history by the French tradition. These letters showed that for the Buenos Aires city happened a significative numbers of exileds from many parts of ibero-americans and europeans (more spanishs), who took the cosmopolitan argentinian capital to appear like a promissory market of cultural beings.

Key-words: Portinari; epistlegrafy; cultural area. 